\title{
Regio- and Stereoselective Fungal Oxyfunctionalisation of Limonenes
}

Rüdiger Kaspera ${ }^{\mathrm{a}}$, Ulrich Krings ${ }^{\mathrm{a}}$, Michael Pescheck ${ }^{\mathrm{b}}$, Dieter Sell ${ }^{\mathrm{b}}$, Jens Schrader ${ }^{\mathrm{b}}$, and Ralf G. Berger ${ }^{\mathrm{a}, *}$

a Zentrum für Angewandte Chemie der Universität Hannover, Institut für Lebensmittelchemie, Wunstorfer Str. 14, D-30453 Hannover, Germany.

Fax: +49-511-7 62-45 47. E-mail: rg.berger@lci.uni-hannover.de

b Karl-Winnacker-Institut der DECHEMA e. V., Theodor-Heuss-Allee 25, D-60486 Frankfurt am Main, Germany

* Author for correspondence and reprint requests

Z. Naturforsch. 60 c, 459-466 (2005); received November 23/December 23, 2004

Selective transformations of limonene by asco- and basidiomycetes were investigated. On the shake flask scale, Penicillium citrinum hydrated $R-(+)$-limonene to $\alpha$-terpineol $[83 \%$ regioselectivity (rs), more than $80 \mathrm{mg} \mathrm{l}^{-1}$ product yield], and Gongronella butleri catalysed the terminal oxidation to yield perillyl alcohol $\left(60 \% \mathrm{rs}, 16 \mathrm{mg} \mathrm{l}^{-1}\right)$. On the laboratory bioreactor scale, Penicillium digitatum produced a peak concentration of $506 \mathrm{mg} \alpha$-terpineol $1^{-1}$ in the fed-batch mode, equivalent to a theoretical yield of $67 \%$, and no volatile by-products were found. Fusarium proliferatum transformed $R-(+)$-limonene enantiospecifically to cis-(+)carveol $\left(98.6 \%\right.$ ee, more than $35 \mathrm{mg}^{-1}$ product yield) and $S$-(-)-limonene predominantly to trans-(-)-carveol $(96.3 \%$ ee). Pleurotus sapidus selectively dehydrogenised the accumulating trans-(-)-carveol to the corresponding enantiopure $R-(-)$-carvone. The results show that a careful selection of strain and bioprocess parameters may improve both the yield and the optical purity of a desired product.

Key words: Limonene, Oxyfunctionalisation, Stereoselectivity

\section{Introduction}

Bioactive monoterpenoids derived from both limonene enantiomeres are among the most frequently investigated products of terpene biotransformations. Especially some of the mono-oxidised derivatives, such as carvone, perillaldehyde, $\alpha$-terpineol or linalool oxide are value-added products that are used as potent flavours, fragrances, pharmaceuticals, fungistatics, and enzyme inhibitors (Duetz et al., 2003; Grassmann et al., 2002; Schrader and Berger, 2001; Sime et al., 2000). The little odour active precursor limonene, the main constituent of Citrus essential oils, occurs in large quantities as a waste stream of Citrus oil processing representing a cheap starting material (Duetz et al., 2003; Ohloff, 1994).

Regio- and enantioselectivity of a volatile molecule are often responsible for characteristic properties in flavour perception. The different perception of the carvone enantiomers $[(S)-(+)$ caraway, $(R)-(-)$ mint] is one of the best known examples of stereoselective odour recognition. The stereoselective introduction of the hydroxy functionality is, therefore, one of the main objectives of flavour biotechnology. Previous investigations on limo- nene transformations have demonstrated at least five different degradation pathways (van der Werf et al., 1999b) which often co-exist without selectivity. For instance, the bacterial transformation of limonene by Pseudomonas aeruginosa reached a maximum concentration of $0.63 \mathrm{~g} \mathrm{l}^{-1}$ carvone and $0.24 \mathrm{~g} \mathrm{l}^{-1} \alpha$-terpineol in $200 \mathrm{ml}$ shake flasks (Acosta et al., 1996). The basidiomycete Pleurotus sapidus, when supplied with $(R)$ - or $(S)$-limonene via the gas phase, yielded more than $0.1 \mathrm{~g}^{-1}$ carveol and carvone (Onken and Berger, 1999) in all possible enantiomer forms. Only a strain of Rhodococcus opacus hydroxylated $(R)$-limonene stereospecifically to yield (+)-trans-carveol with 94 to $97 \%$ ee and with no by-products (Duetz et al., 2001a). This enantioselectivity is crucial for the generation of enantiopure carvone, accessible through the subsequent oxidation, for example, by R. erythropolis (van der Werf and Boot, 2000). Apart from the often found lack of regio- and stereoselectivity, another drawback of cell-based transformations is the enzymatic attack of the primary products of oxidation. For instance, the formation of perillyl alcohol was always followed by the oxidation to perillaldehyde and perillic acid followed by $\beta$-oxidation (Duetz et al., 2001b; 
Chang and Oriel, 1994). As both disadvantages likewise occur with chemosynthesis, there is a strong demand for improved biotransformations for the asymmetric synthesis of terpenoids.

The paper summarises results from an extended screening of 50 asco- and basidiomycete species in an attempt to explore their catalytic potential in limonene transformation. The transformation of $(R)$-(+)-limonene to $\alpha$-terpineol was selected to demonstrate the up-scaleability, and the transformation of limonene isomers to carveol isomers to prove enantiospecificity.

\section{Materials and Methods}

\section{Strains}

Amariella mellea (CBS 100.12), Aspergillus niger (DSM 737), Botrytis cinerea (DSM 1179), Chaetomium cochloides (DSM 1909), Chaetomium globosum (DSM 1962), Fusarium proliferatum (DSM 762), Grifola frondosa (CBS 480.63), Gongronella butleri (DSM 2917), Penicillium digitatum (DSM 62840), Penicillium citrinum (DSM 1179), Pleurotus euosmus (DSM 5331), Pleurotus ostreatus (DSM 5339), Pleurotus sajor-caju (DSM 1020), Pleurotus sapidus (DSM 8266) were obtained from the culture collections of DSMZ, Braunschweig, Germany and Centraalbureau voor Schimmelcultures (CBS), Baarn, The Netherlands. The strains were maintained on yeast agar slants.

\section{Cultivation}

Standard medium was prepared as described by Onken and Berger (1999). For the screening and shake flask experiments, cultures (200 ml volume) were inoculated with $10 \mathrm{ml}$ of $5 \mathrm{~d}$ old pre-cultures which were grown on the same medium and homogenised with an Ultra-Turrax (Janke \& Kunkel, Germany) prior to inoculation. Cultivation was performed on an orbital shaker (Multitron, Infors, Bottmingen, Switzerland) at $150 \mathrm{rpm}$ and $24^{\circ} \mathrm{C}$. The cultivation medium of Penicillium digitatum was composed of $10 \mathrm{~g} \mathrm{l}^{-1}$ glucose, $20 \mathrm{~g}^{-1}$ malt extract, $10 \mathrm{~g} \mathrm{l}^{-1}$ peptone and $5 \mathrm{~g} \mathrm{l}^{-1}$ yeast extract. The $\mathrm{pH}$ was adjusted to 6.5 by $\mathrm{HCl}$ and the medium was autoclaved for $20 \mathrm{~min}$ at $121^{\circ} \mathrm{C}$. The inoculum was prepared by washing a $10 \mathrm{~d}$ old cultivation plate with $5 \mathrm{ml}$ sterile medium and then transferring the medium with spores to a $1000 \mathrm{ml}$ Erlenmeyer flask containing $400 \mathrm{ml}$ medium. The flask was incubated at $27^{\circ} \mathrm{C}$ for $5 \mathrm{~d}$ on an orbital shaker (Certomat-R, B. Braun, Melsungen) at
$120 \mathrm{rpm}$. The bioreactor used (KLF, Bioengineering, Switzerland) had a working volume of 2.71 and a total volume of 3.7 l. It was equipped with a disc stirrer, a dissolved oxygen probe and a $\mathrm{pH}$ electrode. Cultivation was started by adding $200 \mathrm{ml}$ inoculum to 2.51 medium which was autoclaved in situ prior to use. The initial agitation speed was $400 \mathrm{rpm}$, the aeration rate $0.05 \mathrm{vvm}$ (volume air per volume reactor and minute), the temperature $27^{\circ} \mathrm{C}$; the initial $\mathrm{pH}$ after inoculation was 6.3 and was not controlled during fermentation. A metal shell excluded light from the bioreactor. The final biomass concentration was determined by measuring dry cell weight after harvesting and homogenising the total bioreactor content; $4 \mathrm{ml}$ samples were filtered through dried, pre-weighed filter paper and then dried at $105^{\circ} \mathrm{C}$ to constant weight.

\section{Conversion experiments}

Conversion experiments in shake flask cultures were started after $3 \mathrm{~d}$ of inoculation of the experimental culture by adding $100 \mu \mathrm{l}(3.4 \mathrm{~mm})$ of (+)limonene (Fluka, > 90\%) directly into the flasks. Samples were taken at least every day. Cultivation of pure medium and of autoclaved mycelium with addition of limonene were performed to estimate non-catalysed chemical transformation. When the glucose concentration in the bioreactor dropped below $1 \mathrm{~g} \mathrm{l}^{-1}$ (after $70-73 \mathrm{~h}$ ) the biotransformation was started by raising the speed of agitation to $500 \mathrm{rpm}$ and adding $0.84 \mathrm{ml}$ limonene. Subsequently, $0.84 \mathrm{ml}$ of the precursor was added every $24 \mathrm{~h}$. During fed-batch fermentation portions of glucose were additionally supplemented to increase the actual concentration from 0 to $2 \mathrm{~g} \mathrm{l}^{-1}$ every $24 \mathrm{~h}$ (immobilised enzyme glucose analyser, YSI 2700 Select, Yellow Springs, OH, USA).

\section{$G C$ analysis of terpenoids in whole cell extracts}

Samples of cultures were centrifuged at $2,000 \times g$. To $2 \mathrm{ml}$ of supernatant $0.2 \mathrm{~g}$ of sodium chloride were added and the liquid was extracted with $4 \mathrm{ml} n$-pentane/diethyl ether mixture (azeotropic $1: 1.12)$. After centrifugation the organic phase was dried with anhydrous sodium sulfate and injected into a Fisons GC 8360 gas chromatograph equipped with a cool on-column injector, CW $20 \mathrm{M}$ column $(30 \mathrm{~m} \times 0.32 \mathrm{~mm}$ i.d. $\times 0.4 \mu \mathrm{m})$, and a flame ionisation detector using a temperature program starting at $100{ }^{\circ} \mathrm{C}(3 \mathrm{~min})$ to $220^{\circ} \mathrm{C}$ with a 
rate of $5^{\circ} \mathrm{C} \min ^{-1}$. Quantification was done by electronic integration using internal standard calibration $(50 \mu \mathrm{g}$ camphor per extract).

\section{Identification of products}

Transformation products were identified by high resolution GC-MS using a Fisons GC 8000 gas chromatograph and a Fisons MD 800 mass selective detector [interface: $230{ }^{\circ} \mathrm{C}$; ion source: $200{ }^{\circ} \mathrm{C}$; quadrupole: $100{ }^{\circ} \mathrm{C}$; EI $(70 \mathrm{eV})$, scan range $\mathrm{m} / z 33$ to 400] under the same chromatographic conditions as for the GC-FID and the spectra obtained were compared with mass spectra from libraries (NIST, Wiley; van Dyk et al., 1998) and retention times of authentic standards [limonene, carvone $(R / S)$, perillyl alcohol, perillaldehyde, $\alpha$-terpineol, limonene epoxide, dihydrocarveol (Fluka, > 99\%), carveol as mixture of (-)-isomers (Aldrich, $>97 \%)$ ].

Enantiomeric distribution of carveol isomers was measured using a double oven gas chromatograph (Sichromat 2-8, Siemens) equipped with a PTV (programmable thermal vaporiser), a CW $20 \mathrm{M}$ capillary column in one oven and a life Tswitching device to cut onto a chiral $\beta$-cyclodextrin (Cyclosil-B., J \& W Scientific) column (temperature program: $\mathrm{CW} 20 \mathrm{M}$ column: $50{ }^{\circ} \mathrm{C}-3 \mathrm{~min}$, $4{ }^{\circ} \mathrm{C} \min ^{-1}, 220^{\circ} \mathrm{C}-10 \mathrm{~min}$; chiral column: $50^{\circ} \mathrm{C}-$ $3 \mathrm{~min}, 4^{\circ} \mathrm{C} \min ^{-1}, 100{ }^{\circ} \mathrm{C}-20 \mathrm{~min}, 1^{\circ} \mathrm{C} \min ^{-1}$, $220^{\circ} \mathrm{C}$ ). Identification of enantiomers was performed by authentic standards.

\section{Results}

\section{Regioselectivity of limonene transformation}

50 Basidiomycete and ascomycete species were cultivated in the presence of $(R)-(+)$-limonene. Hydroxylation, epoxidation, hydration and dehydrogenation reactions were observed. Hydroxylation reactions in positions allylic to the 1,2- or 8,9double bond of limonene were preferred. Regioselectivity (rs) was calculated as the percentage of oxygen atoms introduced at carbon atoms of the substrate molecule (Fig. 1). The terminal hydroxylation at the C7-position of limonene to perillyl alcohol by Gongronella butleri with approximately $60 \%$ rs (96 h transformation time) was unusual, particularly because the primary alcohol was not oxidised further to perillaldehyde. Penicillium $\mathrm{ci}$ trinum transformed $(R)$-limonene to $\alpha$-terpineol with $83 \%$ rs. Kinetic investigation showed a maximum product accumulation of $80 \mathrm{mg} \mathrm{l}^{-1}$ after $9 \mathrm{~d}$

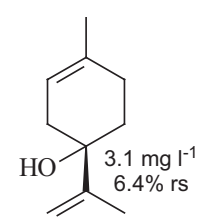

4-hydroxymentha-1,8-dien
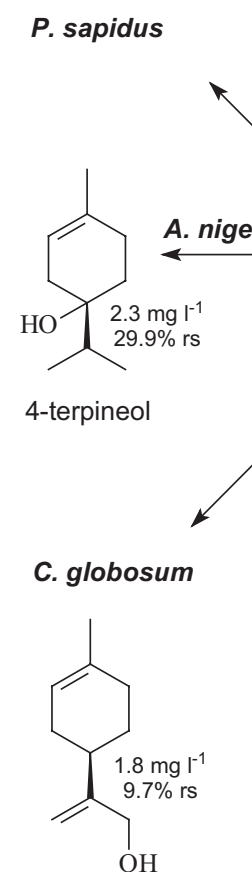

$\mathrm{OH}$

p-mentha1,8(10)-dienol 4-terpineol

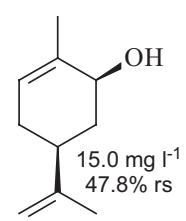

cis-carveol

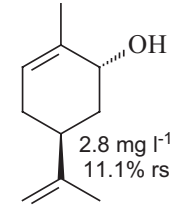

trans-carveol
Fig. 1. Regioselectivity of the (R)-(+)-limonene hydroxylation in submerged cultures of selected strains $[3 \mathrm{~mm}$, transformation time $96 \mathrm{~h}$, orbital shaker at $150 \mathrm{rpm}$, $24{ }^{\circ} \mathrm{C}$, product concentration in $\mathrm{mg} \mathrm{l}^{-1}$, regioselectivity (rs) calculated as the percentage portion of hydroxylation products].

of transformation (conversion yield 17.4\%). Very similar results were obtained with a strain of $P$. digitatum. A significant chemical hydration of limonene started at $\mathrm{pH}$ values below three only.

\section{Bioreactor experiments}

As this product concentration was the highest of all shake flask experiments, $P$. digitatum was inoculated into a lab-scale bioreactor to elucidate up-scalability. The fungus required approximately $70 \mathrm{~h}$ to form adequate biomass and to completely consume the glucose. By maintaining a minimum 


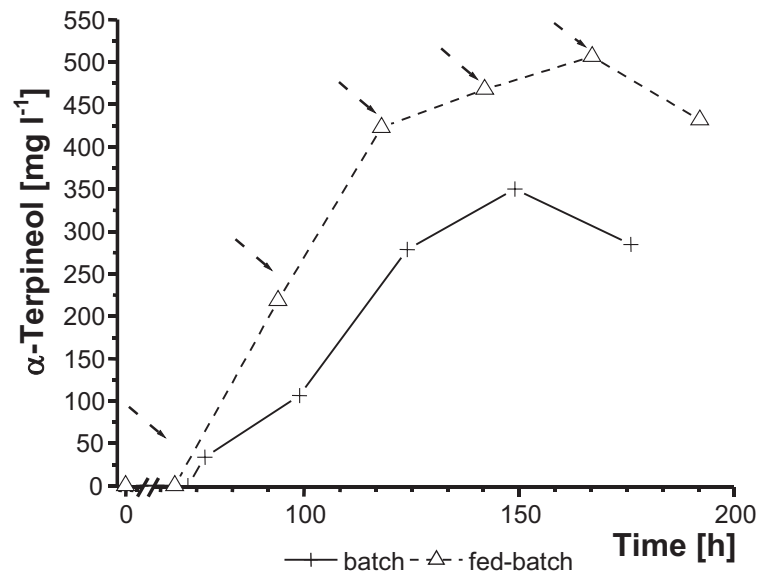

Fig. 2. Comparison of $\alpha$-terpineol formation by $P$. digitatum in batch and fed-batch mode. In both fermentations the biotransformation was started after total completion of the glucose ( $t=73 \mathrm{~h}$ batch, $t=70 \mathrm{~h}$ fed-batch) by addition of $0.84 \mathrm{ml}$ limonene, which was repeated every $24 \mathrm{~h}$. In the fed-batch mode glucose was additionally supplemented to increase the actual concentration from 0 to $2 \mathrm{~g} \mathrm{l}^{-1}$ every $24 \mathrm{~h}$ indicated by arrows.

glucose concentration during the biotransformation period (fed-batch), a maximum product concentration of $506 \mathrm{mg} \mathrm{l}^{-1} \alpha$-terpineol was achieved after $127 \mathrm{~h}$ (Fig. 2). In the batch mode, where no further glucose was added after its completion, $350 \mathrm{mg} \mathrm{l}^{-1} \alpha$-terpineol were formed in $76 \mathrm{~h}$. The maximum molar conversion of $67 \%$ (i.e. related to the total amount of limonene added) already occurred after a biotransformation time of $24 \mathrm{~h}$ in the fed-batch fermentation and remained nearly constant for further $24 \mathrm{~h}$, compared with $31 \%$ maximum molar conversion after $51 \mathrm{~h}$ in the batch mode (Fig. 3). The final cell dry weight in the fedbatch was $4.5 \mathrm{~g} \mathrm{l}^{-1}$, and $4.2 \mathrm{~g}^{-1}$ in the batch fermentation. The precursor limonene was not detected in the samples from either bioreactor during fermentation.

\section{Enantiopure carveols}

For the generation of enantiopure carvones, limonene has to be regio- and stereospecifically oxidised to carveol. The basidiomycetes and ascomycetes selected showed a different ratio of formation of carveol isomers (Table I). In contrast to ascomycetes, basidiomycetes such as Pleurotus species generated all four possible carveol isomers in almost equal quantities. As an exception, Amariella mellea formed predominantly trans-carveol.

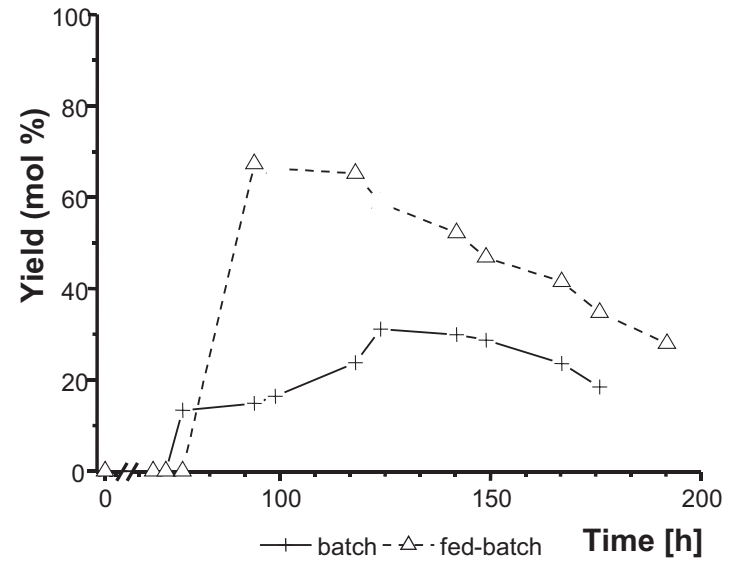

Fig. 3. Comparison of product yield of batch and fedbatch cultivation. The yield refers to the total amount of limonene added.

Following the carveol formation over a period of $7 \mathrm{~d}$ it was found that $P$. sapidus transformed limonene in a constant ratio (1:1) of cis/trans-isomers (Fig. 4). In contrast, ascomycetes such as Chaetomium species, generated predominantly cis-carveol (Table I, Fig. 4). The catalysis of Chaetomium globosum was not very selective at the beginning, but turned into a stereoselective reaction to yield cis-carveol (more than 95\% diastereomeric excess, de) after $2 \mathrm{~d}$. The most selective $(R)-(+)$-limonene transformation was observed with Fusarium proliferatum yielding the cis-carveol isomer with $98.4 \%$ de and an enantiospecificity of $99.8 \%$ ee (enantiomeric excess) for the cis-(+)-carveol from the very beginning. In comparison, the basidiomycete Grifola frondosa started with the generation of more than $95 \%$ de of cis-carveol, but lost its selectivity after $2 \mathrm{~d}$ of cultivation approaching a cis/trans-carveol distribution similar to the chemical blank sample $(65: 35 \mathrm{w} / \mathrm{w})$. The concentrations of carveols in transformation experiments were much higher than those of limonene autoxidation which gave less than $0.5 \mathrm{mg}^{-1}$ carveol under conditions (Table I).

The highest concentration of $35 \mathrm{mg} \mathrm{l}^{-1}$ enantiopure cis- $(+)$-carveol accumulated in $(R)-(+)$-limonene supplemented cultures of Fusarium proliferatum after $22 \mathrm{~h}(6.6 \%$ molar yield, Fig. 5). The transformation of the $(S)$ - $(-)$-enantiomer yielded a maximum of $12 \mathrm{mg}^{-1}$ and a trans/cis-ratio of 76.4 to $22.4 \%$. The cis-(+)- and trans-(-)-diastereomers were of high enantiopurity (trans $90.5 \%$ ee and cis $96.3 \%$ ee, Table I). Preliminary attempts 
Table I. Carveol concentration, distribution and enantiomeric excess in submerged cultivation of selected basidioand ascomycetes after $96 \mathrm{~h}$ of transformation ( $3 \mathrm{~mm}$ limonene, orbital shaker at 150 rounds per min, $24^{\circ} \mathrm{C}$ ).

\begin{tabular}{|c|c|c|c|c|c|}
\hline \multirow[b]{2}{*}{ Substrate } & \multirow{2}{*}{$\begin{array}{l}\text { Carveol } \\
{\left[\mathrm{mg} \mathrm{l}^{-1}\right]}\end{array}$} & \multicolumn{2}{|c|}{$\%$ of isomers } & \multicolumn{2}{|c|}{$\%$} \\
\hline & & trans & cis & $\begin{array}{c}\operatorname{cis}-(+) / \\
\operatorname{cis}-(-)\end{array}$ & $\begin{array}{c}\text { trans }-(+) / \\
\operatorname{trans}-(-)\end{array}$ \\
\hline \multicolumn{6}{|l|}{$(R)-(+)$-Limonene } \\
\hline Amariella mellea & 4.3 & 76.5 & 23.5 & - & - \\
\hline Grifola frondosa & 3.8 & 47.4 & 52.6 & - & - \\
\hline Pleurotus eиosmus & 5.3 & 46.7 & 53.3 & - & - \\
\hline Pleurotus ostreatus & 9.7 & 43.2 & 56.8 & - & - \\
\hline Pleurotus sajor-caju & 5.3 & 51.5 & 48.5 & - & - \\
\hline Pleurotus sapidus & 9.8 & 47.2 & 52.8 & $41.9 / 58.1$ & $48.3 / 51.7$ \\
\hline Ascomycetes & & & & $\begin{array}{c}\% \text { ee } \\
\text { cis-(+) }\end{array}$ & $\begin{array}{c}\% \text { ee } \\
\text { trans-(-) }\end{array}$ \\
\hline Chaetomium cochloides & 6.3 & 4.3 & 95.7 & 99.4 & - \\
\hline Chaetomium globosum & 7.3 & 3.3 & 96.7 & 99.5 & - \\
\hline Fusarium proliferatum & 30.6 & 0.8 & 99.2 & 99.8 & - \\
\hline$(S)-(-)$-Limonene & & & & & \\
\hline Fusarium proliferatum & 13.8 & 76.9 & 22.4 & 90.5 & 96.3 \\
\hline
\end{tabular}

,- Not determined.
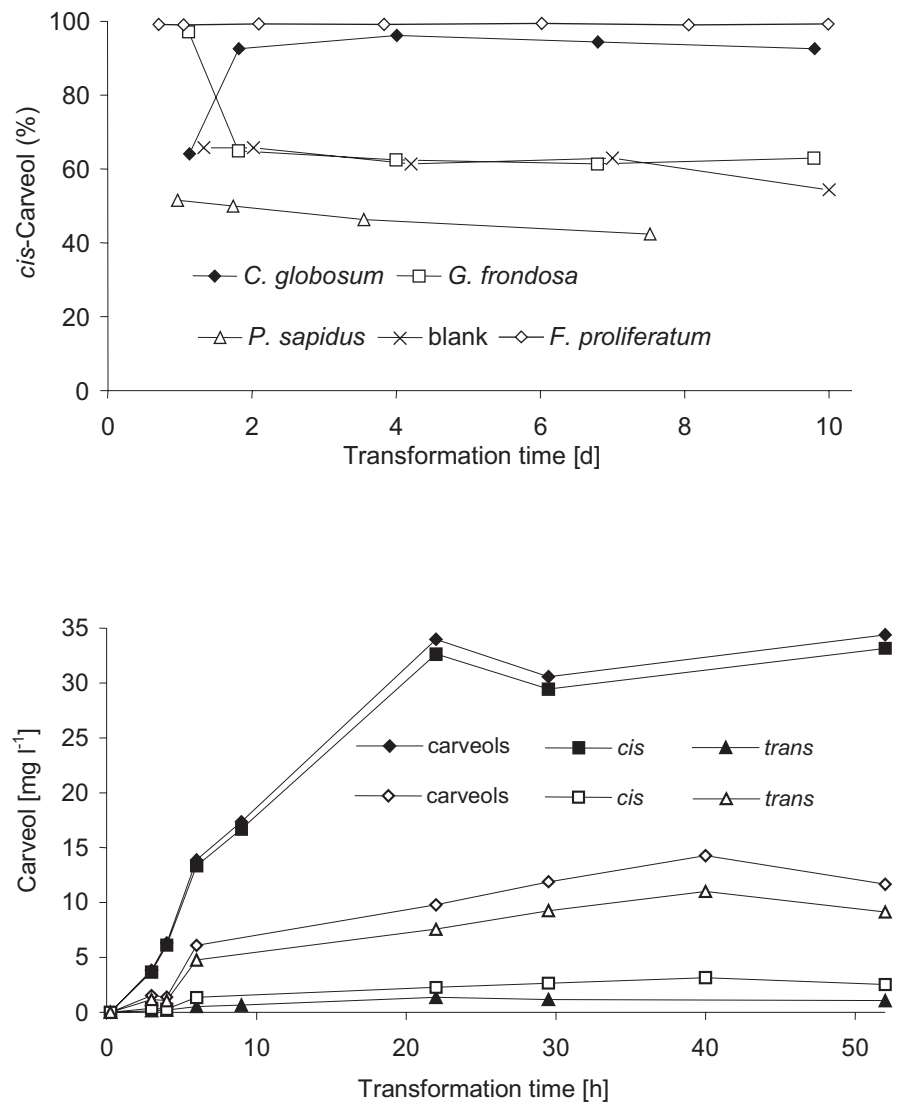

Fig 4. Stereoselectivity of the biotransformation of $(R)-(+)$-limonene by different basidiomycetes, cis-carveol portion of the generated carveol isomers (limonene dosage $3 \mathrm{~mm}$ in $100 \mathrm{ml}$ medium, $24{ }^{\circ} \mathrm{C}$, orbital shaker at $150 \mathrm{rpm})$.

Fig. 5. Time course of carveol generation from $(R)-(+)$ - (solid symbols) and $(S)-(-)$-limonene (open symbols) catalysed by Fusarium proliferatum (substrate dosage $3 \mathrm{~mm}$ ). 
to isolate active enzymes from one of the species failed; neither a cooled ball mill nor grinding of the frozen pellets in various buffers allowed a successful solubilisation.

For the subsequent oxidation of enantiopure carveol to the corresponding carvone submerged pellets of Pleurotus sapidus were used. Kinetic investigations showed that enantiopure (-)-carveols were transformed into enantiopure carvone (>99\% ee). Carvone and carveol reduction products, such as dihydrocarvone and neo-dihydrocarveol were also formed (data not shown). TransCarveol was preferentially converted up to $94 \%$ yield within $4 \mathrm{~d}$, whereas only $55 \%$ cis-carveol was oxidised in the same time.

\section{Discussion}

$(R)-(+)$-Limonene forms the major volatile constituent in Citrus essential oil (up to 97\%), while $(S)-(-)$-limonene predominates in conifer resins (up to $90 \%$ ). The limonenes possess little odour activity and are prone to off-flavour formation and polymerisation after exposure to oxygen. Therefore, they are separated from their natural sources and form a waste stream of 50,000 to 100,000 tons per year (Ziegler, 1998). This turns the compound into one of the most favourable starting materials for chemical and biochemical conversion processes. A recent review described five major microbial transformation pathways (van der Werf et al., 1999b). The fungal species of the present screening showed little formation of epoxide and 1,2-diol, as was shown for a Rhodococcus (van der Werf et al., 1999a), but operated the perilla, the carvone, the isopiperitone and the $\alpha$-terpineol pathways. In contrast to prokaryotic transformer strains, a broad range of mentha-skeleton based alcohols was found indicating a larger enzymatic diversity (Fig. 1).

While some fungi accumulated a considerable number of oxyfunctionalised products, others were distinguished by a pronounced regioselectivity. The regioselective generation of perillyl alcohol by $G$. butleri, for example, was superior to the bacterial transformation by a Myobacterium sp. (Duetz et al., 2001b) in showing no subsequent oxidation to perillaldehyde. The best regioselectivity, however, was observed for the hydration of the 8,9double bond of limonene to $\alpha$-terpineol catalysed by Penicillium species (Fig. 1). Few microbial hydratases have been isolated; the one from Pseu- domonas was described as a transmembrane protein (Cadwallader et al., 1992). Furthermore, cytochrome P450-monooxygenases, as a part of a multienzyme complex, were postulated for the formation of $\alpha$-terpineol (Tan and Day, 1998).

A scale-up from the shake flask to the bioreactor is supposed to increase process efficiency, because the chemical and physical enviroment is much better controllable. While scale-up experiments quite often do not meet expectations, $\alpha$-terpineol formation by Penicillium digitatum was increased immediately (Fig. 2). One reason for the approximately $45 \%$ higher product concentration in the fed-batch fermentation may be the ample supply of the required reduction equivalents for the enzymes formed by intracellular cofactor regeneration as no significant increase in biomass was observed in the fed-batch mode. Problems are still the loss of the precursor via the exhaust air and possibly its total catabolic degradation, as indicated by the failure to recover limonene from the nutrient medium during the process. It is assumed that the true product yield, calculated in relation to the unknown, actually available amount of precursor was much higher than the maximum $67 \%$ of the theoretical yield (Fig. 3). With respect to productivity, the optimum biotransformation time of the fed-batch process was $48 \mathrm{~h}$ resulting in a product formation rate of $8.8 \mathrm{mg} \mathrm{l}^{-1} \mathrm{~h}^{-1}$. This exceeded batch fermentation which resulted in a product formation rate of approximately $5.94 \mathrm{mg} \mathrm{l}^{-1} \mathrm{~h}^{-1}$ over the same period of time. In addition to the good yields, one great advantage of a biotransformation with this organism is its high selectivity. No unwanted byproducts were detected during the whole fermentation period which significantly facilitates downstream processing.

Most of the aforementioned mono-oxyfunctionalisation reactions are believed to be catalysed by cytochrome P450-monooxygenases, enzymes that occur in eukaryotic cells as membrane-bound proteins requiring a separate $\mathrm{NAD}(\mathrm{P}) \mathrm{H}$-dependent reductase for the electron transfer (van den Brink et al., 1998). Fungal mechanisms of the stereospecific hydroxylation of limonene are not well understood. For the generation of racemic carveol by basidiomycetes (Table I, Fig. 4) a two-step mechanism is proposed via an intermediary allylic carbocation or radical. The transient cation or radical can rearrange along the double bond which inevitably results in the loss of the stereochemical infor- 
mation at C4. Non-specific introduction of the oxygen atom then leads to the formation of all four possible stereoisomers of carveol. Upon carveol oxidation an enantiomeric distribution of $67 \%(R)-(-)-$ to $33 \%(S)-(+)$-carvone was observed, regardless of the limonene enantiomer fed (Onken and Berger, 1999).

The stereoselective carveol formation by ascomycetes, such as $F$. proliferatum, gives evidence for an enzymatic mechanism different from the one working in basidiomycetes (Fig. 5). Using $(R)-(+)-$ limonene deuterated at C6 and C3 as the substrate and cells of Mentha species the abstraction of the C6-deuterium was proved during a hydroxylation by a selective cytochrome P450-monooxygenase (CYP71D18) (Wüst and Croteau, 2002). Kinetic studies showed that the binding energy of the substrate to the heme and a hydrophobic binding motive were responsible for a rigid substrate orientation and, therefore, caused a regio- and stereospecific hydroxylation. During the cis-(+)carveol genesis of $F$. proliferatum, formation of the regioisomer isopiperitenol was observed, a by-product also occurring in Mentha.

In contrast to Pleurotus sapidus, Fusarium proliferatum did not form measurable amounts of carvone, but converted both limonene enantiomers: $(R)-(+)$-limonene to cis-(+)-carveol, and $(S)-(-)$ limonene predominantly to trans- $(-)$-carveol. Further oxidation of the enantiopure terpene alcohols yields $(R)-(-)$-carvone [from trans- $(-)$-carveol], and $(S)-(+)$-carvone (Fig. 6). However, transformation of $(R)-(+)$-limonene using a Rhodococcus opacus strain resulted in the formation of trans-(+)-carveol (Duetz et al., 2001a). Obviously, two hydroxylating enzymatic activities with opposite stereospecificity occur in these microorganisms. During characterisation of limonene degrading enzymes from $R$. erythropolis, both (+)and (-)-limonene degrading activities were found in the same cell fractions after chromatography. It was suggested that the enzymes involved converted both limonene enantiomers stereospecifically (van der Werf et al., 1999b). In mint plants two separate monooxygenases, with nearly identical amino acid sequence, are responsible for the regioselective hydroxylation of limonene in C3- or C6-position, respectively (Lupien et al., 1999).

In order to oxidise enantiopure carveol to the corresponding carvone, $P$. sapidus was identified

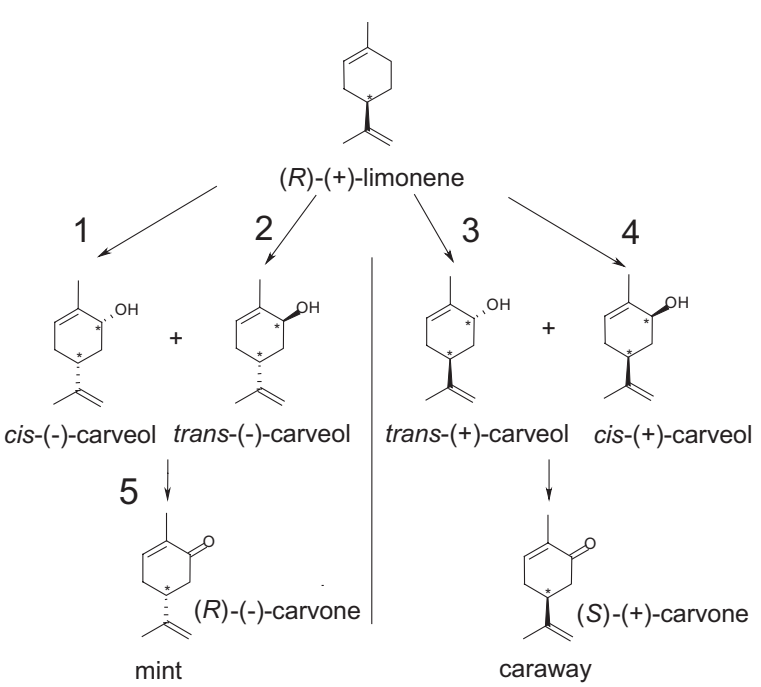

Fig. 6. Generation of enantiopure carvones by enantioselective limonene hydroxylation and subsequent dehydrogenation (all pathways from 1 to 5 by Pleurotus sapidus, pathway 3 Rhodococcus opacus, pathways 2 and 4 Fusarium proliferatum).

as a suitable catalyst for the second step of an integrated bioprocess. The substrate specifity of the carveol dehydrogenase activity [trans- $(-)$-carveol as the predominantly accepted isomer] was similar to the activity observed in Rhodococcus erythropolis DCL14 (van der Werf et al., 1999a). This substrate selective oxidation was also be used in a bioprocess to obtain enantiopure cis-(-)-carveol by racemic separation (Tecelao et al., 2001).

In summary, regio- and stereoselective transformation of the $(R / S)$-limonenes opens access to flavour active terpenoids, such as $\alpha$-terpineol, perillyl alcohol and both carvone enantiomers with high ee-values. The results indicate that basidiomycetes are the more versatile catalysts, but ascomycetes are more suitable to introduce oxygen atoms stereospecifically than basidiomycetes.

\section{Acknowledgement}

We are grateful for the support by the Federal Minister of Education and Research (BMBF 0330062) and by Deutsche Bundesstiftung Umwelt, DBU (AZ 13053/17). The project is part of the joint initiative project "Biologisch aktive $\mathrm{Na}$ turstoffe - Chemische Diversität" at the University of Hannover. 
Acosta M., Mazas N., Mejias E., and Pino J. (1996), Obtencion de aromatizantes mediate biotransformacion del limoneno. Alimentaria 272, 73-75.

Cadwallader K. R., Braddock R. J., and Parish M. E. (1992), Isolation of $\alpha$-terpineol dehydratase from Pseudomonas gladioli. J. Food Sci. 57, 241-244.

Chang H. C. and Oriel P. J. (1994), Bioproduction of perillyl alcohol and related monoterpenes by isolates of Bacillus stearothermophilus. J. Food. Sci. 59, 660-662.

Duetz W. A., Fjallman A. H., Ren S., Jourdat C., and Witholt B. (2001a), Biotransformation of D-limonene to (+)-trans-carveol by toluene grown Rhodococcus opacus PWD4 cells. Appl. Environ. Microbiol. 67, 2829-2832.

Duetz W. A., Jourdat C., and Witholt B. (2001b), Process for the preparation of perillyl alcohol. European Patent Application, EP 1236802.

Duetz W. A., Bouwmeester H., van Beilen J. B., and Witholt B. (2003), Biotransformation of limonene by bacteria, fungi, yeast, and plants. Appl. Microbiol. Biotechnol. 61, 269-277.

Grassmann J., Hippeli S., and Elstner E. F. (2002), Plant defense and its benefits for animals and medicine: Role of phenolics and terpenoids in avoiding oxygen stress. Plant Physiol. Biochem. 40, 471-478.

Lupien S., Karp F., Wildung M., and Croteau R. (1999), Regiospecific cytochrome P450 limonene hydroxylases from mint (mentha) species: cDNA isolation, characterisation, and functional expression of (-)-4S limonene-3-hydroxylase and (-)-4S-limonene-6-hydroxylase. Arch. Biochem. Biophys. 368, 181-192.

Ohloff G. (1994), Scent and Fragrances. Springer-Verlag, Berlin.

Onken J. and Berger R. G. (1999), Effects of $R-(+)$-limonene on submerged cultures of the terpene transforming basidiomycete Pleurotus sapidus. J. Biotechnol. 69, 163-168.

Schrader J. and Berger R. G. (2001), Biotechnological production of terpenoid flavor and fragrance compounds. In: Biotechnology, Vol. 10: Special Processes (Rehm H. J., ed.). Wiley-VCH, Weinheim, Chapter 13 , pp. $374-422$
Sime J. T., Cheetham S. P. J., Gradley M. L., and Banister N. E. (2000), Use of sesquiterpenes for inhibiting oxidative enzymes. US Patent Application, US $6,054,490$.

Tan Q. and Day D. F. (1998), Organic co-solvent effects on the bioconversion of $(R)-(+)$-limonene to $(R)-(+)-$ $\alpha$-terpineol. Process Biochem. 33, 29-37.

Tecelao C. S. R., van Keulen F., and da Fonseca M. M. R. (2001), Development of a reaction system for the selective conversion of trans-( - )-carveol to (-)-carvone with whole cells of Rhodococcus erythropolis DCL14. J. Mol. Catal. B: Enzym. 11, 719-724.

van den Brink H. M., van Gorcom R. F. M., van der Hondel C. A. M. J. J., and Punt P. J. (1998), Cytochrome P450 enzyme systems in fungi. Fungal Genet. Biol. 23, 1-17.

van der Werf M. J. and Boot A. M. (2000), Metabolism of carveol and dihydrocarveol in Rhodococcus erythropolis DCL14. Microbiology 146, 1129-1141.

van der Werf M. J., van der Ven C., Barbirato F., Eppink M. H. M., de Bont J. A. M., and van Berkel W. J. H. (1999a), Stereoselective carveol dehydrogenase from Rhodococcus erythropolis DCL14. A novel nicotinoprotein belonging to the short chain dehydrogenase/ reductase superfamily. J. Biol. Chem. 274, 2629626304.

van der Werf M. J., Swarts H. J., and de Bont J. A. M. (1999b), Rhodococcus erythropolis DCL14 contains a novel degradation pathway for limonene. Appl. Environ. Microbiol. 65, 2092-2102.

van Dyk M. S., van Rendsburg E., Rensburg I. P. B., and Moleleki N. (1998), Biotransformation of monoterpenoid ketones by yeasts and yeast-like fungi. J. Mol. Catal. B: Enzym. 5, 149-154.

Wüst M. and Croteau R. B. (2002) Hydroxylation of specifically deuterated limonene enantiomers by cytochrome P450 limonene-6-hydroxylase reveals the mechanism of multiple product formation. Biochemistry 41, 1820-1827.

Ziegler E. (ed.) (1998), Flavourings. Wiley-VCH, Weinheim. 